\title{
Organizational Imaginary and Tacit Dimension of Knowledge: a Case Study in a Telecommunications Company
}

\author{
Marcia Caldas Pitrowsky ${ }^{\dagger}$ \\ Instituto Brasileiro de Administração Pública e Apoio Universitário do Rio de Janeiro \\ Isabel de Sá Affonso da $\operatorname{Costa}^{\Omega}$ \\ Universidade Estácio de Sá \\ Denise Medeiros Ribeiro Salles ${ }^{\#}$ \\ Universidade Federal Fluminense
}

\begin{abstract}
This study investigated the relationship between organizational imaginary and tacit dimension of knowledge creation, according to Nonaka and Takeuchi (1997) model, in a telecommunications company. This choice is justified because such segment is highly competitive and knowledge-intensive. Qualitative approach and case study strategy were used, based on documentary analysis, semi-structured interviews and application of projective techniques in workshops. The results showed that the lack of organizational intention concerning the collective commitment to knowledge creation, in a manner clearly articulated by senior management, fails to leverage the existing fertile grounds for innovation, having in view the spontaneous commitment shown by its employees with the image of the company, which is great in their point of view.
\end{abstract}

Keywords: Organizational imaginary. Knowledge creation. Individual-organization identification. Tacit and explicit knowledge.

\footnotetext{
* Author for correspondence:

${ }^{\dagger}$ Master in Business Administration and Management Development from Universidade Estácio de Sá - RJ Title: Specialist Consultant in Personnel Management and Institutional Development of the Instituto Brasileiro de Administração Pública e Apoio Universitário do Rio de Janeiro Address: Avenida Engenheiro Richard, Grajáu - Rio de Janeiro - RJ - Brazil E-mail: marcia.pitrowsky@gmail.com Phone: (21) 99477-4924
}

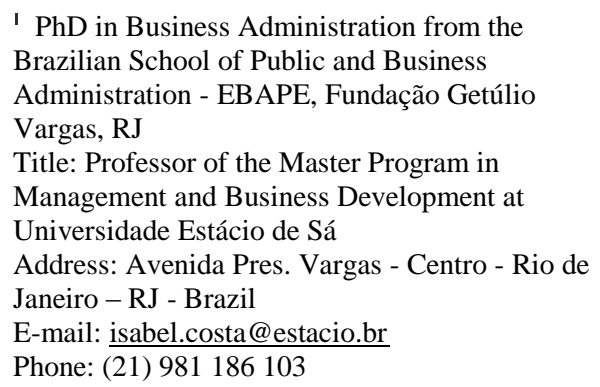

\author{
${ }^{¥} \mathrm{PhD}$ in Management from the \\ Brazilian School of Public and \\ Business Administration - EBAPE, \\ Fundação Getúlio Vargas, RJ \\ Title: Associate Professor III, \\ Universidade Federal Fluminense \\ Address: Avenida Almirante Ary \\ Parreiras, Niterói - RJ - Brazil \\ E-mail: denisesalles@id.uff.br \\ Phone: (21) 999688255
}

Editor's Note: This paper was accepted by Emerson Mainardes. 


\section{INTRODUCTION}

$\mathrm{n}$ a context of highly dynamic markets, organizations must increasingly create and innovate processes, products and services to ensure competitiveness. Thus, companies need to adopt management models oriented towards organizational learning and innovation as well as capture the maximum energy from its employees, aiming at organizational success. To this end, sensitizing and mobilizing these contributors,

through the imaginary, around the same commitment seems to be a way of achieving the desired competitive advantage.

Several theorists have used the concept of the imaginary, relating it to the social context, such as Enriquez (1972), or to the organizational context, such as Larçon and Reitter (1979), to designate the fantasy shared by a management team or a group of employees of an organization, seeking to show the influence of this imaginary on the identity of the company, on the organizational culture and on the leadership.

According to Lapierre (1989), the imaginary relates simultaneously to the set of representations that individuals make about the internal subjective reality and about the external objective reality, serving as a link between them and representing the most important qualitative element which constitutes the personality of the individual. At the same time, as recognized by Maffesoli (2001), the imaginary goes beyond the individual and permeates the collective sphere, so that the individual imaginary ultimately matches the imaginary of a group to which the individual belongs. Thus, the imaginary creates a bond, works through interaction and can be understood as "the state of mind of a group, a country, a nation state, a community" (MAFFESOLI 2001, p. 76).

Recognition of the importance of the imaginary can also be inferred in Nonaka and Takeuchi (1997), who argue that companies cannot create knowledge for themselves without the involvement, commitment and identification of individuals with the values and ideals of the organization. Based on such approach, the authors defend, in their theoretical model of knowledge creation, the idea that flexible and qualitative elements, such as ideals, values, emotions, images and symbols, are essential in this process.

The importance of the tacit dimension of knowledge in Nonaka and Takeuchi (1997) shows no understanding of the organization as a machine for processing information, but as a living organism with a culture that recognizes that not all knowledge is created and learned in a purely conscious manner, since it is the result of the internalization of experiences lived by individuals, i.e. it is not always possible to convey knowledge only through formal education 
and training. Therefore sharing the understanding of what the company is, what direction it is taking, how to interpret the environment seems more relevant than processing objective information. Such pleas relate to the deeper understanding of knowledge creation in organizations, which includes the recognition of the relationship between the imaginary and the tacit knowledge and how it occurs in the context of organizations.

In such perspective, we highlight the contribution of Lapierre (1989) on the relation between the imaginary and knowledge. The author argues that knowledge and science as well as all human actions and practices find, in fact, its foundations in the imaginary, in the universal fantasy in which the human being finds (their) truth, making the world intelligible to themselves.

This study intended to contribute to the understanding of the relationship between knowledge creation and organizational imaginary, showing the relevance of subjective and psychodynamic aspects that house, in the creation and knowledge conversion process, their protagonists: individual and organization. The survey was developed as an opportunity to search for evidence that encourages reflection on the importance of the individual, subjectivity and organizational imaginary in knowledge creation in organizations.

\section{THEORETICAL REFERENCE}

\subsection{IMAGINARY AND ORGANIZATIONS}

For Altman (1995), the year 1709 marks the emergence of the concept of imagination, with the work of Giambattista Vico; this stated that subjects such as languages, literature and studies of fables constituted the foundation of human interpretation of the world. Vico maintained that the universe was the great principle of human knowledge; for him, the knowledge would begin with the image. This understanding brought by Vico became one of the bases that would take Lapierre (1989) to defend the imaginary as a basis for knowledge construction.

Altman (1995) expresses the view that, at present, the imagination becomes important driven by the need to survive the economic and industrial leaders who seek to train their staff and those responsible for research and development activities, in order to escape the narrow contours of technical and industrial thought, turning them into inventive and creative professionals. In this sense, the need arises for companies to develop their capacity for learning and self-organization. Morgan (1996) corroborates this idea based on the metaphor of the organization as a brain, according to which these skills are important for companies to make front to the requirements of adaptation to intense competitive scenario. This process 
requires changing attitudes, which could require, for many organizations, the need for change in the way they see the world, in their vision of the future, their values and beliefs, a process which refers to issues that permeate the notion of organizational imaginary.

Enriquez (2002) argues that contemporary organizations present themselves as cultural, symbolic and imaginary systems. To the extent that organizations are no longer seen only as production systems or social systems, other elements come to be considered in management policies. In this context, to channel the productive power of individuals, we must construct a discourse that gives legitimacy to the more "human" image of the company, providing a reference model for the set of collective behaviors, which the author calls the direction through affection.

Management through affection can be understood as a manifestation of the recognition by organizations of the link between imagination, action and achievement. As pointed by Maffesoli (2001, p. 76-77):

The imaginary, even if it is difficult to define it, of course presents a rational reasonable element, but also other parameters such as the oneiric, the playful, the fantasy, the imaginative, the affective, the irrational, the dreams, that is, the mental potentiating constructs of so called practices. Somehow, the man acts because he dreams of acting. What I call "emotional" and "affectual" are organic dimensions of the action from the spirit.

To Enriquez (2002), organizations have the option to choose between two types of imaginary to present to individuals who are part of it: the deceptive and the motor imaginary. The imaginary is misleading when the organization tries to arrest the subject into the trap of their own desires of narcissistic affirmation by seeking recognition and power. In addition, the organization ensures them to be able to offer protection from the risk of breaking their identity and from the anguish of disintegration, awakened and fed for life in society, offering them solid breastplates of organizational status and role. By making these promises, the organization tends to replace them by their own imagination. Concerning the appearance of imaginary deception, Freitas (2006) points out that in this way, the organization is expressed at the same time as a divine institution that encompasses both the lactating mother and protective father, seeking to occupy the entire psychic space of the individual.

The second type is the motor imaginary, which allows the individual to get carried away by their creative imagination in their work environment, without feeling constrained by rules. It allows individuals to live together with what is different, with the changes and the possibility of rupture. It is an imaginary that encompasses the other, the spontaneity, the new experiences, freedom of expression and questioning thoughts. To Enriquez (1997) and Freitas 
(2006), by opening space to question the organization, motor imaginary is much less developed than the misleading imaginary, since this ensures the admiration for the organization and nourishes the dependence of individuals in relation to the alleged community formed therein.

Enriquez (1997) emphasizes that organizations have sought to make sense of the actions of its members through the affirmation of certain values. The primary difference is that today, all organizations knowingly and willingly try to build such systems of values, aiming to model the thoughts, inducing the essential behavior to their dynamics. To the author, if the organization manages to make its mark on the thinking and the mental apparatus of its employees, it can then rejoice and be deemed to have come to join its contributor in the culture it proposes and imposes and to develop motivation for contribution in achieving the objectives.

Also according to Enriquez (1997), an institution empties when it does not create values and socialization processes, when it cannot be constituted as a solid symbolic reference and an identifying reference in not presenting itself as a space where the imaginary unfolds and unconsciousness and feelings find objects to be invested.

Still on the path towards understanding the force that the imaginary has on individualcompany relationships, Amado (2002) points out some social and psychological phenomena that relate to the weakening of large balance systems and social reproduction, such as political ideologies; religions; traditional family, among others. For this author, the occurrence of this set of phenomena contributes to strengthen the broader crisis of cultural, social and individual identity that undermines the Western world today and the company has taken center stage in this problem by providing an organizational identity that in some way aims to fill the void of individual and social references today.

Freitas (2002), to support this enormous drawing power of corporations over individuals, brings the psychoanalytic concept of transference which, according to Laplanche and Pontalis (1991, p. 514), "is the process by which the desires and unconscious emotions are updated in certain objects, in a type of relationship experienced in the past." The relations experienced by the subjects within companies reflect positions that are close to the ones of the Oedipal stage. The competition for places, positions, power and influence approaches that of the child that wants his father's place or anyone who interferes with their access to the object of love, personified by the mother. In general Freitas concludes (2002, p.70): "What organizations request is a strange marriage of autonomy and child dependency." 
The organization, when presented to individuals as "almighty", places them directly on the core of the issue of the search for identity, affirmation of a compact and flawless unit and that fears fragmentation in the center of their imagination (ENRIQUEZ, 2002).

\subsection{KNOWLEDGE IN ORGANIZATIONS}

Morgan (1996) proposes the image of the brain as a metaphor for the functioning of organizations: the brain is a system capable of learning to learn and is structured as a holographic system, in which the skills required for the whole are embedded in parts. The use of the metaphor of the brain may be a viable way to develop the organization, the process of flexible and creative action, especially when the intention is to improve organizational learning, information processing and self-organization.

Similarly, authors such as Stewart (1996), Nonaka and Takeuchi (1997), Sveiby (1998) and Tonet and Peace (2006) argue about the importance of a supportive environment for the construction of knowledge within a holistic organizational view that facilitates interactions of each part to the whole, as well as managers that encourage the participation of all. The trust and cooperation between the various actors are identified as the skills necessary for the knowledge flow. The availability and willingness of individuals who have the knowledge and those who receive it are also cited as factors influencing the knowledge sharing process.

\subsubsection{The Model of Knowledge Creation by Nonaka and Takeuchi}

The choice of the Nonaka and Takeuchi (1997) model for this research stems from the focus elements that are fundamental for the knowledge creation process, such as: valuing the incorporation of direct personal experience; the organic worldview that values the subjective knowledge and intuitive intelligence; the relevance of the questions which act as engines for the establishment of a resonance that stimulates commitment and spontaneous and creative actions of individuals in the organization. In this sense, the model provides a clear relationship between the imaginary and knowledge creation, a problem that is the subject matter of this investigation.

What constitutes the cornerstone of epistemology proposed by Nonaka and Takeuchi (1997) is the distinction between tacit and explicit knowledge, a concept also espoused by Davenport and Prusak (2001), affluent of the thought of Polanyi (1959; 1983) and Kuhn (2000), which recognizes the human and tacit dimension of knowledge as well as the interaction between intuition and imagination in the discovery process. 
Tracking the thought of Polanyi (1983), Kuhn (2000) postulates that learning features a type of process that develops itself not only with the help of verbal means. This process reflects a tacit knowledge that is learned by doing science and not simply acquiring rules for doing it. Knowledge and understanding of the world are not provided to individuals by external events. Rather, they seek to make world objective through essentially subjective processes. Thus, all modes of symbolic understanding are composed of words, concepts, ideas, facts and observations, denoting concepts more strongly activated in the mind through selective, meaningful and shared perception of the world than aspects that are external to the process. Thus, these representations do not refer to external reality, but are actually tools used by the individual to grasp and deal with what is perceived on the outside.

For Nonaka and Takeuchi (1997), the key to knowledge creation lies in the mobilization and conversion of tacit knowledge, being a central concern of the authors the creation of organizational knowledge, as opposed to the individual knowledge. The theory they postulate focuses on the levels of knowledge-creating entities: individual, group, organizational and inter-organizational levels. Their theory proposes the existence of two dimensions: the epistemological and the ontological dimension of knowledge creation. From them the spiral of knowledge creation begins, which arises when the interaction between tacit and explicit knowledge dynamically increases, from the lower, individual ontological level to the higher, organizational level.

\subsubsection{The Model of Five Stages of Organizational Knowledge Creation Process: the Four Modes of Conversion and the Five Enabling Conditions}

It is from the four modes of knowledge conversion: socialization; externalization; combination and internalization, promoted by the five enabling conditions at the organizational level: organizational intention; autonomy; fluctuation and creative chaos; redundancy and requisite variety, which configures the integrated model of organizational knowledge creation, using the basic constructs (developed within the theoretical context and incorporating the time dimension) of the theory. The model should be seen as an ideal example of the process, composed of five stages: (1) sharing of tacit knowledge; (2) creation of concepts; (3) justification of the concepts; (4) construction of an archetype; and (5) Interactive dissemination of knowledge, as illustrated in Figure 1. 


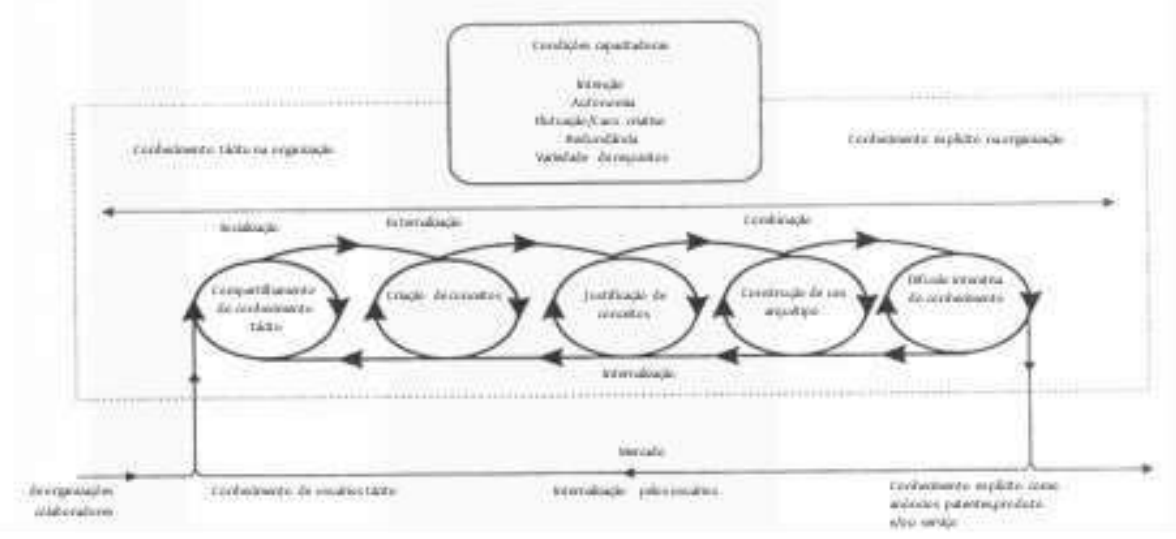

Figure 1 - Model of The Five Stages of Organizational Knowledge Creation Source: Nonaka and Takeuchi (1997)

The research aimed to investigate, in a knowledge-intensive company, the relationship between organizational imaginary and tacit dimension of creation, conversion and interactive dissemination of knowledge. We sought to further identify the existence or not of an intentional organizational imaginary that privileged the tacit dimension in the process stages, as well as existing enabling conditions and the institutional mechanisms used for such process.

\section{METHODOLOGY}

The choice of the approach must be anchored in the nature of the problem being treated. Thus, the qualitative approach is the most appropriate to the subject matter of this research. Also, the option for the use of projective techniques in data collection, in order to favor the emergence of more subjective aspects, also contributed to the choice of a qualitative approach.

The projective techniques value the symbolic, highlighting that everything that is presented in the context lived is covered with meanings and can bring the key to the interpretation of this context (AUGRAS, 1998). These techniques operate by the following principle: the individual, through a stimulus, designs subjective aspects that, for some reason, he would not spontaneously. They constitute unstructured and indirect ways of asking that encourage individuals to express their motivations, beliefs, attitudes and feelings about the issues underlying the study, revealing the particular ways of seeing, feeling and interpreting situations.

As a methodological strategy adopted was the case study which is appropriate when issues such as "how" and "why" are asked, when the researcher has little control over events 
and when the focus is on contemporary phenomena inserted in some context of real life (Yin, 2005).

\subsection{CHOOSING THE COMPANY}

The studied company, here called XCOM as a way to maintain secrecy about its identity, was due to the fact that it belongs to the telecommunications segment, which is knowledge and innovation intensive, fundamental aspects in a business with a high degree of competition and competitiveness. XCOM has a solid position in the segment in which it operates, has about seven thousand employees and has a Technology Reference Center that constitutes a laboratory for testing and simulation, where all equipment and networks that serve customers are represented. The site also includes suppliers and customers around cutting-edge technologies that then will be available to all citizens.

The group of participants was composed of 13 individuals selected by the criterion of intentionality between the general staff of XCOM from the response to a formal request made by the company through the internal training network, for participation in two workshops about the subject matter of this study. The workshops have been inserted into the event called "Week of Knowledge", promoted by XCOM as part of a strategy for the dissemination and discussion of the importance of knowledge to the organization.

The criterion for selecting participants aimed at the formation of two groups of employees coming from top level technical positions, middle management and technical and administrative support, placed in different departments of the organizational structure and that had at least a six-month relationship with the company. This composition aimed at the formation of two groups merged in terms of the variety of experiences and perspectives, but without the intention of forming a typical group, able to represent the entire company. The intentionally heterogeneous configuration of the profile of survey participants potentiated the seizure of the collective imagination through the perceptions and peculiarities of the various actors involved. Likewise, this merged structure allowed the understanding of perceptions, and indicators and experiences on the practice of conversion and interactive dissemination of tacit knowledge in day-to-day of the company by subjects with different characteristics with respect to time in the company, training, title and field.

\subsection{THE DATA COLLECTION}

For data collection, workshops, semi-structured interviews and internal and open-access records were used respectively, as in XCOM's website. 
In the study with groups of participants in the two workshops, in seeking a possible relationship between the imaginary and the tacit dimension of knowledge creation, it was necessary to use techniques that would enable to stimulate the expression of emotional, psychological and political dimensions. In similar contexts, instruments that fall in so-called projective techniques have been used in research in the organizational field (PAGÈS et al., 1987; TONELLI and Caldas, 2001; VERGARA and SILVA, 2002). Among these were inserted nonverbal techniques of expression, which, according to Pagès et al. (1987, p. 208), "enable seizing the collective imaginary, that is, the unconscious desires and anxieties experienced in the relationship between individuals and institutions, with collective objects of investment".

The study made use of drawing construction techniques and sentence complementation techniques (VERGARA, 2008) which made it possible to obtain insights on the issues identified below:

a) Technical construction drawings: how each participant perceives the organization and how he or she is represented therein; how the group perceives the organization and how it is represented therein.

b) Sentence Completion Technique: identification of participants' perceptions about the dynamics of the relationship between organizational imaginary and knowledge creation process, from the practice of conversion and interactive dissemination its tacit dimension in the researched organization. To this end, the elements of knowledge creation of Nonaka and Takeuchi (1997) creation model in companies were used as search variables. On that basis, incomplete sentences were created that sought to stimulate the expression of attitudes, procedures, resources and indicators that could be present in the company surveyed.

\subsection{THE USE OF THE WORKSHOP TECHNIQUE}

The choice of the workshop as a technical approach aimed to promote the integration of participants, their mobilization and sensitization for reflection on the topic under study, the encouragement of free expression, allowing a space for non-verbal communication and the understanding of the collective imaginary. Conducting workshops sought to work both the personal level and relational and institutional levels, in which the "I", the "Other" and all the aspects that represent and organize the production characteristics of each were considered. With this purpose, the individual's relationship with the organization was put on the agenda, namely, the design of workshops, providing an environment that favors the emergence of articulated social aspects, from which the participants represented the unconscious expression 
of individual and collective imaginary, around reference axes that sought to articulate the psychological, political and ideological aspects. This type of intervention in groups, according to Pagès et al. (1987), leads rather to the questioning of disruptions than of compliances, rather of conflicts than things that are going well, rather of implicit than of explicit, rather of what is latent than of what is manifest, rather of what is irrational than what is rational. Thus, it enables to exploit the social and mental structures in a dialectical perspective. In this sense, the moderation of groups during the workshops, the choice and organization of the techniques used, the guidelines in conducting the activities, and the processing, analysis and interpretations developed with participants about the individual and collective productions have focused on this objective.

\subsection{THE APPLICATION OF THE DRAWING CONSTRUCTION TECHNIQUE AND SENTENCE COMPLEMENTATION TECHNIQUE}

The techniques were applied during the workshops in three activities, the first two related to the construction of free drawings and third one to sentence complement.

The drawings, which aimed to represent an identity between the individual imaginary and organizational imaginary were developed by participants in the presence of the researcher, from her guidelines, as follows:

1st activity: individual drawing

a) Participants were required to build individually a free creation drawing on the theme: "The company and me: how I perceive the company and how I insert myself in it."

b) The participants were also instructed to post the drawing individually made on the wall provided for this purpose as they finished.

2nd activity: collective drawing

a) The researcher guided the formation of groups for collective construction of a drawing of free creation on the theme "The company and us: how we perceive the company and how we insert ourselves in it."

b) each group was asked to post the drawing on the wall.

After posting on the wall the productions for the two activities, we asked each participant and each group to explain the meaning and their interpretation of the expression on the theme projected in their own drawings (individual and group) and of the others. What they wanted at this stage was not to reach a common understanding of the drawing of each 
individual and every group, but rather favor the collective expression from the representation brought by the drawing of each participant and each group. Then it was asked to each author of the individual drawings and group drawings to assess whether the perception of others reflected or not what they had wished to represent, giving afterwards an explanation of his own drawing or of the group, in the case of collective drawing.

3rd activity: complementation technique

The application of questionnaire with 24 incomplete sentences was performed in the presence of the researcher, from her guidelines. Participants were asked, by working individually, to complement the form with incomplete sentences on "knowledge management in the company," which were based on the assumptions of the model of the five stages of knowledge creation of Nonaka and Takeuchi (1997).

\subsection{TREATMENT AND ANALYSIS OF EVIDENCE}

The method chosen for data analysis was the dialectical method of content analysis, used by Pagès (1987) to capture subjects whose structures are not depicted as a solid frame of each piece, but as contents that come in nuances, with a chain of contradictions articulated to one another. In this sense, Pagès (1987) says, one should not separate the terms of contradictions, with the pretext to analyze them, but rather learn and understand the structure of relations that links each element of the contents brought to others. Thus, this method was adopted because it fit best to the analysis of the object in question, involving the interaction between seemingly opposing concepts such as tacit and explicit dimension of knowledge; individual imaginary and organizational imaginary; objective discourse and subjective discourse; individual and collective spheres; identification and identity in the knowledge creation process in the company. Thus, the choice relates to the characteristics of this method, which combines the dialectic as the art of dialogue, contrast and contradiction of ideas that lead to other ideas and content analysis (BARDIN, 1995), as a means of inducing so that the causes can be investigated (inferred variables) from effects (inference variables or indicators). When they merge, these features allow to form a broader view of the issue under study.

It is noteworthy that, particularly in the analysis of the evidence brought by the representations of the drawings, verbal explanations of participants as to the meanings of their both individual and collective subjective productions added valuable content for later interpretation of representations. Theoretical knowledge and experience of the researcher in psychology, her acting and presence as moderator and facilitator for the workshops, along 
with the theoretical foundations that anchored this study supported the analysis and interpretation of drawings.

In the context of this method of analysis, the following pairs of concepts that emerged from the literature on the subject matter of the study were examined: tacit-explicit; objective discourse - subjective discourse; individual-collective; identity-identification; individual imaginary-organizational imaginary. From this focus, the process of analysis encompasses the following: a) units of discourse and treatment of connections; marking of relevant words; b) extraction of sentences and paragraphs related to the research variables.

In the specific case of the sentence complementation technique, mixed grids were created, in which categories (responses) were defined that were relevant to the purpose of the research, admitting, however, the inclusion of categories (responses) arising during the analysis process. There was the need for subdivision, inclusion or exclusion of categories; the final set of categories was established considering such rearrangement.

\section{ANALYSIS OF RESULTS}

\subsection{ANALYSIS OF THE DRAWINGS: PSYCHOSOCIAL ASPECTS OF GROUPS}

The interpretation of individual and collective drawings favored joint reflection by participants, both in the construction stage of the drawings and in the interpretation stage, giving them a voice so that they could express their perceptions about the subjective meanings of their productions.

Regarding the results obtained with this technique, some common representations and interpretations gained prominence, but showed variations in their form of expression and converged on two major themes: a) the strength of individual-company identification process and the contradictions and conflicts derived therefrom; b) the discomfort brought about by the perception people have of an internal environment which lacks a clearly articulated organizational strategy for the dissemination of values and beliefs that guide the decisions of changes and new concepts created in the company as well as a direction to fulfill the mission in which is invested. In the details of the analysis of the drawings, we attempted to identify the relationships that these topics, brought by subjective expression of XCOM employees, might have with the practices of conversion of tacit-individual knowledge into organizational knowledge, and its interactive dissemination.

On the subject (a), the company was represented in various drawings as being a world that permeates and affects the lives of all people through the high-tech it has, creating 
products and services that capture and transmit information and knowledge to all. As some authors of the drawings have expressed, "it is in our lives; (...) sometimes we are employees, sometimes customers "(collective expression of the "Morning Group"); (...) "In this way, we are affected by the company" (P4).Accordingly, they seem to have a symbiotic relationship with the company that permeates their professional and personal lives. Figures 2 and 3 show these perceptions.

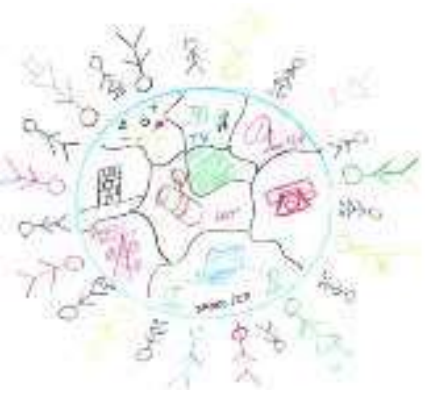

Figure 2 - Morning Group Collective Drawing

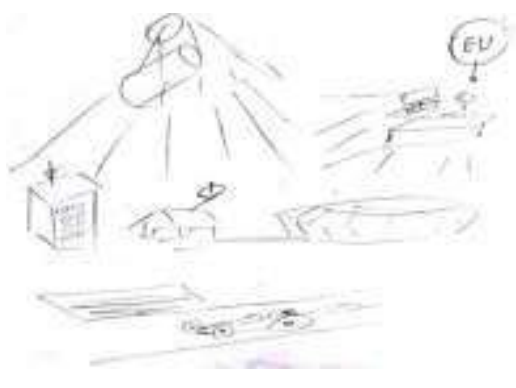

Figure 3 - Individual Drawing P4

The company XCOM was also perceived as a scenery and source of fulfillment of dreams and as a way for professional development and realization of fantasy that the grandeur of the company is dependent upon their support and dedication, which is implemented in the form of selfless and heroic behavior. This fantasy is reflected, for example, in the expression of the collective drawing of the morning group, "(...) even if there are no ideal conditions the company continues to produce and then we have to take the stand and give support." Or yet the collective expression of group A afternoon in the workshop: "(...) despite the lack of internal processes, nothing stands still. No matter how, or even if someone dies" as the drawing of this group expresses (Figure 4). 


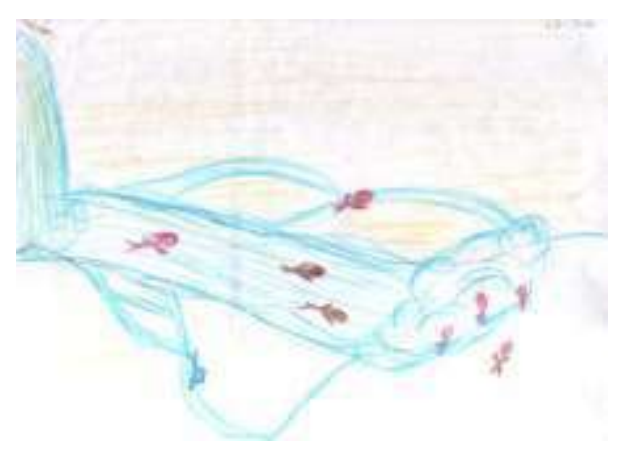

Figure 4 - Collective drawing of group A afternoon (XCOM represented as a spawning. Participants represented as fish struggling against the current to reach the goal of XCOM.)

The contradictions between the strength of identification with the image of the company and the individual imaginary were also represented in some drawings. In the interpretation of drawings, such evidence could be observed in the subjective expression of the conflict between the pleasure of being part of XCOM and the realization that "not everything is so colorful and easy on the pursuit of personal dreams (P12)"; or even the vision of the company as a path to career development, but represented as "a stream that carries us, not always where we want to go (P13)", as shown in the drawings of Figures 5 and 6.

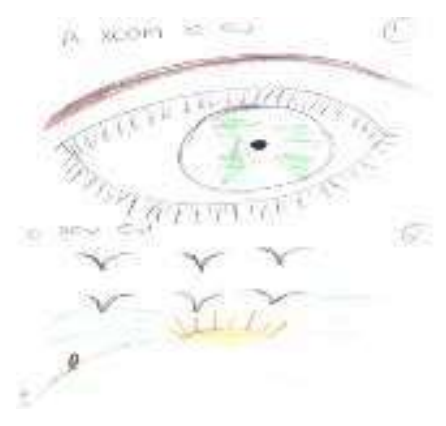

Figure 5 - Individual drawing P12

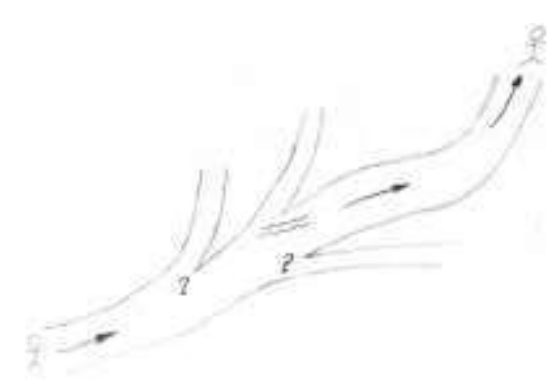

Figure 6 - Individual drawing P13

Another aspect represented and interpreted in the drawings expresses another contradictory element, but it also binds to the individual/company identification process. This study highlights the contradictory when company is seen and represented as a world, but that is, however, composed of a set of isolated people, giving the idea that the model imagined, idealized is not fully realized. That is, it is not realized in a holistic and integrated view of the drawings of the employees that represented in this manner (P6, P2 - Figures 7 and 8). 


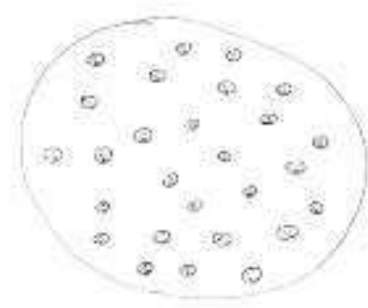

Figure 7 - Individual drawing P6

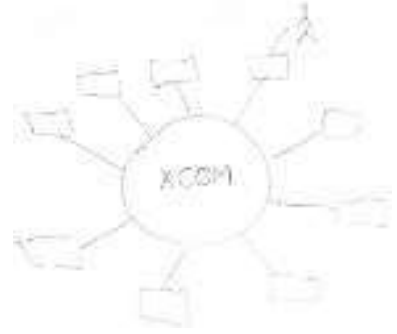

Figure 8 - Individual drawing P2

Related to the topic (b), the interpretations of the drawings also indicated a conflict of perceptions when there is evidence from these representations that, although identified, implemented and committed to XCOM, convey a strong feeling that the company does not offer them an imaginary that, when articulated by top and middle management, defines the game, mission, values and beliefs that guide new concepts and business decisions, generating insecurity. This feeling is brought to them in the form of little systematization of processes and routines in predominantly tacit knowledge, not interactively disseminated, and by the apparent lack of direction, as well as values and beliefs clearly stated by top management.

This somewhat ambiguous characteristic of $\mathrm{XCOM}$ proved to be a point that is uncomfortable to all participants. However this aspect that is shared by this group of employees does not seem to alter the strength of the positive image of the company and the identification with it. Rather, it makes them feel more heroes than victims, because "after all they lead the company to maintain its success"; "(..) despite the lack of internal processes, nothing stands still. No matter how, even if someone dies", were the collective expressions of the "morning group" and "Group A afternoon"

The theme (b) reflected to the participants in the form of lack of structured internal processes and blurring of organizational direction is expressed in various drawings such as $\mathrm{P} 5$, which proves to be a presence in the imaginary of participants. The interpretation of the drawings shows how this aspect brings conflicts before the need for unity on the one hand, and centralization and dependence of people on the other hand, since the company is seen as predominantly tacit, as explained by one of the authors of the drawings: " (...) information and knowledge become power" (P8). Figures 9 and 10 show drawings relating to such perceptions. 


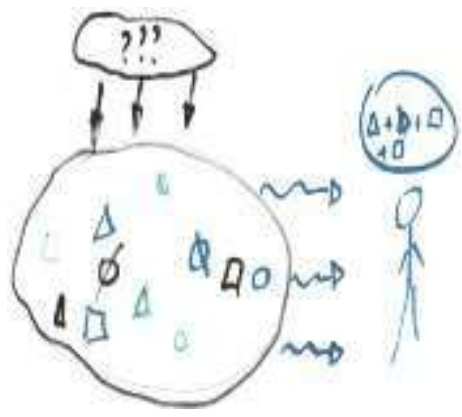

Figure 9 - Individual drawing P5

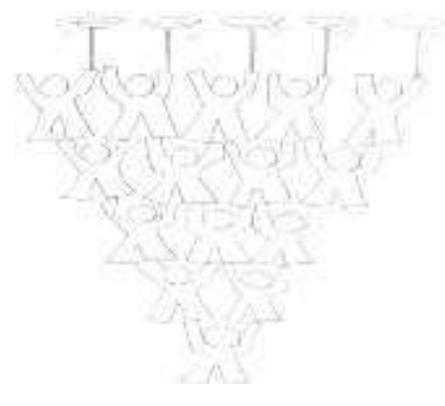

Figure 10 - Individual drawing P8

The consequences of the lack of an organizational intention, which should be made explicit in the form of values, beliefs and ideals was also shown in another drawing. There the author (P3) expressed how this aspect could become ineffective and inoperative the concepts that have not been substantiated by top management. This participant is represented in the company through his drawing as "one swallow that does not make a summer", since the objectives of the area that he manages did not come from the discourse of the company to the action of top management, not being, therefore, as a real value for XCOM (Figure 11).

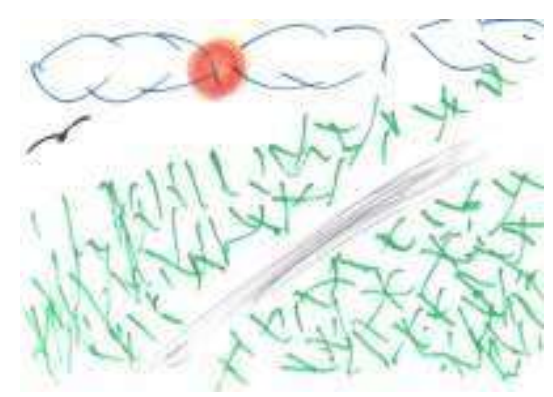

Figure 11 - Individual drawing P3

\subsection{ANALYSIS OF EVIDENCE OBTAINED WITH THE COMPLEMENTATION TECHNIQUE}

(a) Sentences related to the stage of sharing tacit knowledge: the complementation of respondents bring insights that point to some important dichotomies in terms of the variables that should be present at this stage and that were investigated. They relate, first, to the presence of strong identification of participants with the grand image they have of XCOM and their pride to belong to it. Equally strong is the expression of the pleasure they feel in working in the company to the extent that, when they feel challenged and engaged in contributing to 
the company's business, they perform, learn and expand knowledge. However, in contrast, there is among them the perception that the company has an intentionally articulated concern with seeking the collective commitment to knowledge creation. So, the practices aimed at creating a field of interaction that conducts to dialogue and exchange of experiences and at capturing skills through practical observation are perceived as incipient and rare. There were also considered incipient: the work of cross-functional teams with a common goal; establishment of challenging goals by managers; and the granting of autonomy to teams. These practices, proposed in Nonaka and Takeuchi (1997) model seek the facilitation of the process of sharing tacit knowledge; but does not seem to be part of day-to-day of many of the study participants.

(b) Sentences related to the stage of concept creation: the complement of sentences related to the variables that should be present so that this stage of the model materializes as dialogue and collective and cooperative reflection, showed that knowledge at XCOM is mainly tacit and secreted by people and areas. The perceptions identified pointed to the precarious storage practices and access to knowledge necessary for employees to develop the company's business, hindering the conversion of individual knowledge (tacit) into organizational knowledge. The exchange of experiences and group work as a facilitating factor is shown as an isolated view in this study group. Common aspects related to the perception of easy and difficult aspects at this stage bind to the lack of an organizational intention toward the collective commitment around the sharing and transformation of tacit knowledge into explicit knowledge, its interactive dissemination and storage in the company. Another aspect brought by the respondents pointed to the need for awareness and management commitment to show that knowledge is an important value to the success and continuity of the business. In general, barriers to this stage appear, such as: the individualized work; not sharing ideas; centralization of knowledge in people; lack of time; successive changes; and lack of investment in storage technology and access to knowledge.

(c) sentences related to the stage of justification of concepts: the results of the complement of the sentences make it clear how the lack of practical dialogue and collective reflection echoes in this stage of justification of concepts. A recurring question in the sentences concerned the perception of respondents about the lack of clear criteria for justification of concepts created by the company, creating difficulties in understanding and acceptance, and low credibility. The criteria need to be better publicized and communicated, since the participants see them as subjective and under the responsibility of each manager, in 
general being authoritarian and dependent on commitments to the board of directors of the company. The lack of institutionalized practices to facilitate the sharing of experiences makes the knowledge in XCOM mostly tacit, individualized, apparently opening little room for innovation. For Nonaka and Takeuchi (1997), new knowledge is the product of a dynamic interaction between front-line staff, specialists, middle managers and top managers, i.e. all agents are in the innovation process. In the case of XCOM, the evidence points to the centralization of this process in managers and top management.

(d) sentences related to the stage of construction of an archetype: Nonaka and Takeuchi (1997) propose that the process of giving tangibility to the new validated concept is conducted cooperatively between various departments, bringing together different technical skills. Thus, it allows requisite variety and redundancy of information, conditions that facilitate the combination of the new explicit knowledge with existing explicit knowledge and would permit learning by intrusion, also enabling the sharing of tacit knowledge between different actors of innovation involved.

The results of sentence complementation related to the variables of this stage of the model explain several examples of new concepts made tangible cooperatively by employees of XCOM. Should be noted that, although there isn't evidence in XCOM of an intentionally articulated stimulus, before specific needs to solve and expedite matters of day-to-day business, managers and specialists take initiatives to create new concepts, which have been referred and institutionally approved for use by the developed area. Taking evidences into account, despite the absence of an intentional organizational imaginary that stimulates them, the unconscious processes of identification through idealization is what move XCOM's employees in seeking collaboration and contribution to organizational improvements in dayto-day, resembling to what Freitas (2006) calls highly competitive collaboration. On the other hand, individualism and isolation that are present in XCOM, both represented in the drawings and in sentence complementation show as contradictions to the idea of being proud to be part of the team, when giving the individual the illusion of being a hero in pursuit of unattainable goals or at least difficult ones to maintain. This contradiction, according to Freitas (2006), rather strengthen than limits the company, to the extent that it benefits from this game that instills in individuals greater dynamism and desire to win, in addition to searching the deserved recognition and the growing desire of success. For Nonaka and Takeuchi (1997), the dynamic interaction between two opposing sides, false contradictions, ultimately creates a new and different solution. For them, the tacit and explicit knowledge are not two opposite 
sides of a dichotomy, but rather complementary instances that interact and communicate enabling the creation of something new.

On the topic related to the practice of converting existing know-how and technologies internally, as well as promoting interpersonal and interdepartmental cooperation in XCOM, the most recurrent content of types of sentences relates to the overriding need to spread this concept in top management to stimulate the integration between different areas, creating an environment that conducts to the exchange of experiences and focus on knowledge management through the creation of an institutional program.

(e) sentences related to the fifth stage of the model (interactive dissemination of knowledge) regarding practices focused on creating and interactive dissemination of knowledge in their internal environment, for most of the respondents now they are not well defined, with an XCOM stage attempts to initiate the process, but that has much to grow. The vision of the participants is that the company is evolving and advancing in that direction. Some sentences showed that the company, although it has instruments to the effect, would need to overcome cultural barriers. Also, they point out that there is a lack of autonomy for the practice of internal dissemination of knowledge created. To do this, they show that, beyond cultural barriers, it is necessary to overcome the inertia of areas and dependence of the capacity of those who implements them. Thus, the horizontal and vertical fertilization of new knowledge occurs informally from individual initiatives or small groups who do so based on the need for the service.

Regarding the interactive dissemination of knowledge outside the company, the evidence brought by the complementation of sentences show that this practice does not seem to have a strong value in XCOM. It is observed that some participants could not even complete the sentence by claiming ignorance or difficulty in completing it. The vision brought by the content of a representative set of sentences of the respondents is that this mobilization for interactive dissemination of knowledge to the external environment does not happen. Some sentences indicate that there is a movement in this direction, in the form of proposals that are under study. It is important to emphasize that none of the respondents mentioned the Technological Reference Center, maintained by XCOM and that provides its technology in products and services to suppliers and customers.

\section{CONCLUSIONS}

Regarding the issue that is the subject matter of this study, the relationship between organizational imaginary and tacit dimension of knowledge, it was possible to identify, from 
the perceptions brought by participants, that in the organizational imaginary of XCOM perceived and portrayed by them, the lack of a clear expression of the value that the individual/tacit knowledge and its conversion into explicit/organizational knowledge may have. Thus, the study pointed out that management practices planned and articulated by top and middle management to foster an environment that leads to sharing the tacit dimension of knowledge are rare and incipient on organizational day-to-day. In this scenario it is possible to relate the perceived organizational imaginary in XCOM with the eminently tacit characteristic of knowledge in the company, which remains centralized and fragmented in people and areas. On the other hand, the organizational imaginary proved to be in fact a source of identification and reference for individuals in XCOM, not even being created and articulated intentionally

by the company. This identification with the powerful image of XCOM generates by itself spontaneous and creative engagement of employees with the objectives and outcomes of the company, leading them to act as heroes and guardians of the success and greatness of XCOM.

Regarding the existence of enabling conditions for knowledge creation and application of Nonaka and Takeuchi (1997) model, it is observed that these same individuals strongly identified with the image of XCOM express the deficiency and discomfort they feel because of the lack of an organizational intention around the collective commitment to knowledge creation, so clearly stated in the vision, value and belief justified by top management. In this sense, XCOM fails to leverage the existing fertile ground for innovation, in the form proposed by the model of knowledge creation of Nonaka and Takeuchi (1997), in the face of spontaneous commitment shown by its employees around the identification that they have to the image of XCOM, which is grand in their point of view.

The results invite to investigate, in the current context of companies, the value that has been assigned to middle managers to mediate the gap between the company's vision, articulated by top management, and the reality examined by individuals who work on the front lines, which makes the dream placed in the vision come true.

\section{REFERENCES}

ALTMAN, E. O conceito de imaginação: uma história inacabada. In: LAPIERRE, L. (Org.). Imaginário e liderança. São Paulo: Atlas, 1995.

AMADO, G. Coesão organizacional e ilusão coletiva. In: MOTTA, F.; FREITAS, M. E. (Org.). Vida psíquica e organização. Rio de Janeiro: FGV, 2002.

AUGRAS, M. A dimensão simbólica: o simbolismo nos testes psicológicos. Petrópolis: Vozes, 1998. 
CALDAS, M. P.; TONELLI. M. J. Casamento, estupro ou dormindo com o inimigo? Interpretando imagens e representações dos sobreviventes de fusões e aquisições. In: ENCONTRO DOS PROGRAMAS DE PÓS-GRADUAÇÃO EM ADMINISTRAÇÃO (ENANPAD), 25., 2001, Campinas (SP). Anais... Campinas: ANPAD, 2001.

DAVENPORT, T. H.; PRUSAK, L. Conhecimento empresarial. 3. ed. Rio de Janeiro: Campus, 2001.

ENRIQUEZ, E. A organização em análise. Petrópolis: Vozes, 1997.

. Vida psíquica e organização. In: MOTTA, F.; FREITAS, M. E. (Org.). Vida psíquica e organização. Rio de Janeiro: FGV, 2002.

FREITAS, M. E. A questão do imaginário e a fronteira entre a cultura organizacional e a psicanálise. In: MOTTA, F. C. P.; FREITAS, M. E. (Org.). Vida psíquica e organização. Rio de Janeiro: FGV, 2002.

2006.

Cultura organizacional: identidade, sedução e carisma? 5. ed. Rio de Janeiro: FGV,

KUHN, T. S. A estrutura das revoluções científicas. São Paulo: Perspectiva, 2000.

LAPIERRE. L. Imaginário, administração e liderança. Revista de Administração de Empresas, v. 29, n. 4, p. 5-16, 1989.

Imaginário e liderança: na sociedade, no governo, nas empresas e na mídia. São Paulo: Atlas, 1995.

LAPLANCHE, J.; PONTALIS, B. Vocabulário da psicanálise. São Paulo: Martins Fontes, 1991.

LARÇON, J. P.; REITTER, R. Structure de pouvoir et identité de l'enterprise, Paris: Nathan, 1979.

MAFFESOLI, M. O imaginário é uma realidade. Revista Famecos, n. 15, p. 74-82, 2001.

MORGAN, G. Imagens da organização. São Paulo: Atlas,1996.

NONAKA, I.; TAKEUCHI, H. Criação de conhecimento na empresa. Rio de Janeiro: Elsevier, 1997.

PAGÈS, M. et al. O poder das organizações. São Paulo: Atlas, 1987.

POLANYI, M. Personal knowledge: towards a post-critical philosophy. Chicago: The University of Chicago Press, 1958.

The tacit dimension. Gloucester: Peter Smith, 1983.

SILVA, J. R. G.; VERGARA, S. C. Análise comparativa acerca da utilização de desenhos na pesquisa sobre a criação do sentido da mudança organizacional. Organizaçõoes \& Sociedade, v. 9, n. 23, p. 159-169, 2002.

STEWART, T. A. Capital intelectual. Rio de Janeiro: Campus, 1996. 
SVEIBY, K. E. A nova riqueza das organizações. Rio de Janeiro: Campus, 1998.

TONET, H. C.; PAZ, M. G. T. Um modelo para o compartilhamento de conhecimento no trabalho. Revista de Administração Contemporânea, v. 10, n. 2, p. 1-11, 2006

VERGARA, S. C. A utilização da construção de desenhos como técnica de coleta de dados. In: VIEIRA, M. M. F.; ZOUAIN, D. M. (Org.). Pesquisa qualitativa em administração. Rio de Janeiro: FGV, 2004.

Métodos de pesquisa em Administração. São Paulo: Atlas, 2008.

YIN, R. K. Estudo de caso. Porto Alegre: Bookman, 2005. 